\title{
Safety of the association of pegylated interferon and ribavirin in the treatment of chronic viral hepatitis $C$ in the blacks: a ten year observation
}

\begin{abstract}
Background: Sub Saharan population are the most affected by chronic hepatitis C. The interferon- based regimen has been the only available treatment in the last decade. The announced direct acting antivirals will still be associated to the actual regimen. Reports on the safety of these protocols are so far Caucasians-based, and data from sub Saharan populations are lacking.

Aim: To describe the secondary effects of the combination of Pegylated interferon and ribavirin I the treatment of chronic hepatitis $\mathrm{C}$ in black Africans.

Methods: it was a multicenter study in which we included chronic hepatitis $\mathrm{C}$ patients, over ten years, treated by the association of Pegylated interferon-Inf and ribavirin, from all the centers of treatment in the country. Patients should be naïve to this treatment, fulfill the condition of treatment according to manufacturer, namely Hoffmann La Roche. Side effects were recorded during follow up. The base line follow up biological tests included: Liver function tests; full blood count; TSH; kidney function test.

Results: All the patients reported at least one adverse event, related to treatment. The clinical adverse events were dominated by asthenia; flu-like syndrome; head ache and myalgia; we registered 6 cases of depression. The most biological adverse events were of hematologic origin.

Conclusion: The adverse effects related to combination therapy using Pegylated interferon alfa-2a and ribavirin in the treatment of chronic HCV in the blacks, are similar to those indicated by the manufacturer. These adverse tend to be in relation the duration of treatment. Some of them can become intractable, alternative treatment or psychological support from patients association can be helpful.
\end{abstract}

\author{
Volume 2 Issue 5 - 2015
}

\author{
Njoya O, 1,2 Djoukam Tchoupe D, ${ }^{3}$ Mawaguia \\ Woguia JP, ${ }^{4}$ Tagni Sartre M, ${ }^{3}$ Essi MJ,' \\ Ombotto $S,{ }^{5} \mathrm{Nkam} \mathrm{M}^{2}$ \\ 'Research Laboratory on viral Hepatitis and Health \\ Communication, Cameroon \\ 2Department of Medicine, University of Yaoundé I, Cameroon \\ ${ }^{3}$ Centre médical la Cathédrale, Cameroon \\ ${ }^{4}$ Faculty of Medicine and Biomedical Sciences Yaoundé, \\ Cameroon \\ ${ }^{5}$ Higher institute of Medical Technology Yaoundé, Cameroon
}

\begin{abstract}
Correspondence: Njoya O, Department of Internal Medicine and specialties, Faculty of Medicine and Biomedical Sciences, University of Yaoundé I, Research Laboratory on Viral Hepatitis and Health Communication, Po. Box 3495 Yaoundé, Cameroon, Tel 237-699-8I I-7I7, Email oudou_nj@yahoo.fr
\end{abstract}

Received: : July 22, 2015 | Published: : August 28, 2015
Abbreviations: RBV, ribavirin; SVR, sustained virological response; DAAs, direct acting antivirals; FLS, flu-like syndrome

\section{Introduction}

The combination regimen associating a weekly subcutaneous injection of Pegylated interferon (Peg-Inf) and a daily oral dose of ribavirin $(\mathrm{RBV})$ is still is the current treatment of choice for chronic hepatitis $\mathrm{C}$ in the sub-Sahara region. Even some of the awaited new drugs will be combined to the actual regimen, though the duration of those new treatments will be shortened. Racial differences in the achievement of sustained virological response (SVR) has been reported $^{1}$ and black patients has a low rate of SVR, irrespective of .$^{2-4}$ Some studies have already described the adverse effects of PegInf/RBV combination, but nearly all of them were Caucasian-based experiences. The combination of Peg-Inf/RBV has significant adverse effects which can compromise the acceptance and the tolerability of the treatment. These adverse effects are therefore, non-negligible limiting factors which need to be well known and well managed. Each patient finally seems to be a particular case to take care of. The present study has been conducted in a sub-Saharan black community where there are some epidemiological, clinical and biological peculiarities.

\section{Methods}

\section{Patient selection}

We included in this study, chronic hepatitis C patients, treated by the combination of Peg-Inf and RBV and naive to this treatment. To be included in the study, patients should be aged at most 70 years, with an activity score $\geq A 1$ and a fibrosis score $\geq F 2$, they should have completed at least 12 weeks of treatment. By the way, they should fulfill all the conditions of treatment according to manufacturer. We used La Roche manufactured Peg-Inf and RBV. Patients were enrolled after a two steps selection. Firstly, each physician involved in the treatment of viral hepatitis, selects the patients for treatment, according to international guide lines criteria, namely the EASL guide lines. Secondly patients files are reviewed by a committee comprising all the physicians involved in the treatment and follow up of patients suffering from viral hepatitis. Non-inclusion criteria included initial anaemia, long standing co morbidity. We excluded from this study patients who associated an unknown drug to the main treatment.

\section{Study design}

It was a prospective multicenter observational study over a period of 10 years, from January 2005 to December 2014. Investigators were physicians from the 6 centers of treatment of viral hepatitis in Cameroon. Side effects were recorded during follow up. They were either subjective from patient's declarations and recording, or objective from physical examination and the biological tests. Patients enrolled, were given a booklet on which date and time of treatment were recorded, as well as all supposed treatment related adverse effect. These adverse effects were subsequently transcribed in the patient's file by the investigators, after analysis. A physical examination was subsequently performed. The base line follow up 
biological tests included: Liver function tests; full blood count; TSH; kidney function test. We assessed the efficacy by the virological response, and the parameter was the measurement of viral load (HCV RNA). The different assessment time points of the treatment efficacy were weeks 4,8, 12, 24,48 (according to the genotype) and 24 weeks after the end of treatment.

\section{Statistical analysis}

Descriptive statistics were calculated for demographic characteristics and viral load. Patient's characteristics were compared using the Chi-square test. Bivariate and multivariate analysis were performed accordingly, to identify factors independently associated with main adverse effects.

\section{Results}

\section{Study population}

We definitely included 391 patient over a period of 10 years. They were 282 males (72\%) and 109 females (28\%). The genotyping showed 202(51.7\%) of genotype 4 (G4); $102(26.1 \%)$ of genotype 2 (G2) and $87(22.2 \%)$ of genotype $1(\mathrm{G} 1)$. The viral load was high in 239 patients $(61.1 \%)$. Other epidemiological, biological and clinical baseline characteristics are summarized in Table 1.

Table I Patient's Baseline Characteristics ( $\mathrm{N}=39$ I)

\begin{tabular}{|c|c|}
\hline General Characteristics & n (\%) \\
\hline Male & $282(72 \%)$ \\
\hline Female & $109(28 \%)$ \\
\hline \multicolumn{2}{|l|}{ Age Groups } \\
\hline$\leq 50$ & $80(20.5 \%)$ \\
\hline $51-60$ & $266(68 \%)$ \\
\hline $61-70$ & $45(11.5 \%)$ \\
\hline Mean age & $55.5 \pm 6.7$ years \\
\hline \multicolumn{2}{|l|}{ Risk Factors(RF) } \\
\hline Invasive surgery & $105(26.8 \%)$ \\
\hline STP or $\mathrm{Cl}^{*}$ & $78(19.9 \%)$ \\
\hline Dental care & $59(15.1 \%)$ \\
\hline Blood transfusion & $55(14.1 \%)$ \\
\hline $\mathrm{VHC}$ in entourage & $16(4.1 \%)$ \\
\hline Invasive exploration & $4(1.1 \%)$ \\
\hline No evident RF & $74(18.9 \%)$ \\
\hline \multicolumn{2}{|l|}{ Virology } \\
\hline \multicolumn{2}{|l|}{ Genotype(G) } \\
\hline G4 & $202(51.7 \%)$ \\
\hline G2 & $102(26.1 \%)$ \\
\hline GI & $87(22.2 \%)$ \\
\hline \multicolumn{2}{|l|}{ Viral Load } \\
\hline High(>800 000 IU/mL) & $239(61.1 \%)$ \\
\hline $\operatorname{Low}(\leq 800000 \mathrm{IU} / \mathrm{mL})$ & I52(38.9\%) \\
\hline \multicolumn{2}{|l|}{ ALT Level } \\
\hline Normal & $87(22.3 \%)$ \\
\hline Abnormal & $304(77.7 \%)$ \\
\hline \multicolumn{2}{|l|}{ Fibrosis Score } \\
\hline $\mathrm{F} 2$ & $205(52.4 \%)$ \\
\hline F3 & $16 \mathrm{I}(4 \mathrm{I} .2 \%)$ \\
\hline F4 & $25(6.4 \%)$ \\
\hline \multicolumn{2}{|l|}{ Co Morbidities** } \\
\hline Hypertension & $66(16.8 \%)$ \\
\hline Alcohol $\geq 50 \mathrm{~g} /$ day & $63(16.1 \%)$ \\
\hline Obesity & $49(12.5 \%)$ \\
\hline
\end{tabular}

* Scarification; Tattoos; Piercing; Collective Immunization.

**Before Treatment.

\section{Compliance, adherence and efficacy}

Out of the 391 patients enrolled, a total of $6(1.53 \%)$ patients interrupted their treatment because of adverse events related to the treatment. Of these cases, one was a severe depression. The remaining patients received at least $80 \%$ of their scheduled doses of drugs. Efficacy of the treatment was assessed by the measurement of HCV RNA concentration at different time points.SVR was achieved in $48 \% ; 36.1 \% ; 22 \%$ for G2, G4 and G1 respectively (Figure 1).

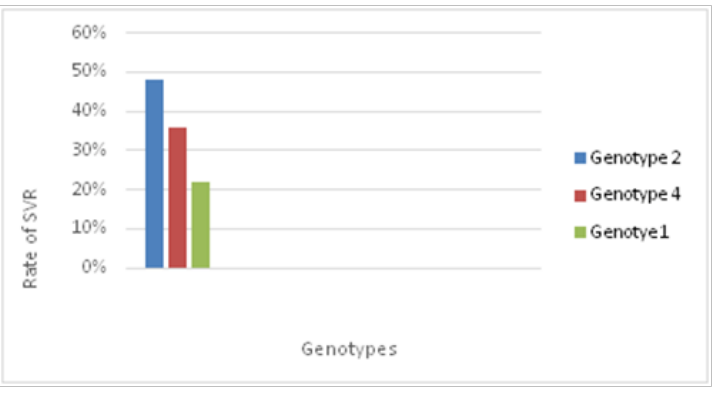

Figure I Rate of SVR according to genotype.

\section{Safety analysis}

All the patients reported at least one adverse event, considered as related treatment side effect. These sides effects, which were either clinical or biological, could be mild (grade 1), moderate 'grade 2), severe, indicating modification of the treatment (grade3) very severe indicating to stop treatment (grade 4). We considered as major sides effects, those which occurred in at least $10 \%$ of the sample (Table 2 ).

Table 2 Clinical side effects $(\mathrm{N}=391)$

\begin{tabular}{ll}
\hline Clinical Signs* & $\mathbf{n ~ ( \% )}$ \\
\hline General & \\
Asthenia & $241(61.6 \%)$ \\
Flu-like syndrome & $121(30.9 \%)$ \\
Weight loss & $59(15.1 \%)$ \\
Neuro psychiatric & \\
Headache & $117(29.9 \%)$ \\
Irritability & $73(18.7 \%)$ \\
Insomnia & $43(11 \%)$ \\
Depression & $6(1.5 \%)$ \\
Drowsiness & $6(1.5 \%)$ \\
Loss of memory & $6(1.5 \%)$ \\
Lack of concentration & $5(1.3 \%)$ \\
Dermatologic/Muscular & \\
Myalgia & $117(29.9 \%)$ \\
Pruritus & $82(20.9 \%)$ \\
Hyper pigmentation & $6(1.5 \%)$ \\
Skin rash & $5(1.3 \%)$ \\
Alopecia & $5(1.3 \%)$ \\
Acromia & $5(1.3 \%)$ \\
Eczema & $2(0.5 \%)$ \\
Digestive & \\
Anorexia & $46(11.7 \%)$ \\
Dyspepsia & $45(11.5 \%)$ \\
Diarrhea & $11(2.8 \%)$ \\
Dysphagia & $6(1.5 \%)$ \\
Respiratory or Cardio Vascular & \\
Cough & $106(27.1 \%)$ \\
Hoarseness & $11(2.8 \%)$ \\
Shortness of breath & $9(2.3 \%)$ \\
Ding &
\end{tabular}

*One Patient could have Many Side Effects 
Clinical adverse events: The major clinical adverse events were dominated by asthenia $(61.6 \%)$ the flu-like syndrome (30.9\%); head ache and myalgia for a similar rate of $29.9 \%$ (Table 2). We registered 6 cases of depression (1.5\%) among which, one became intractable, so that we stopped the treatment. Neither the rate nor the severity of the side effects was related to the genotype (Figure 2). Even though not that frequent in our study, it is worth pointing out some peculiarities of dermatological side effects in the blacks namely, the acromia (Figure 3 ) and the alopecia (Figure 4) and the eczema (Figure 5). The clinical side effects appeared quite often by the 12th week and disappeared progressively after the end of the treatment.

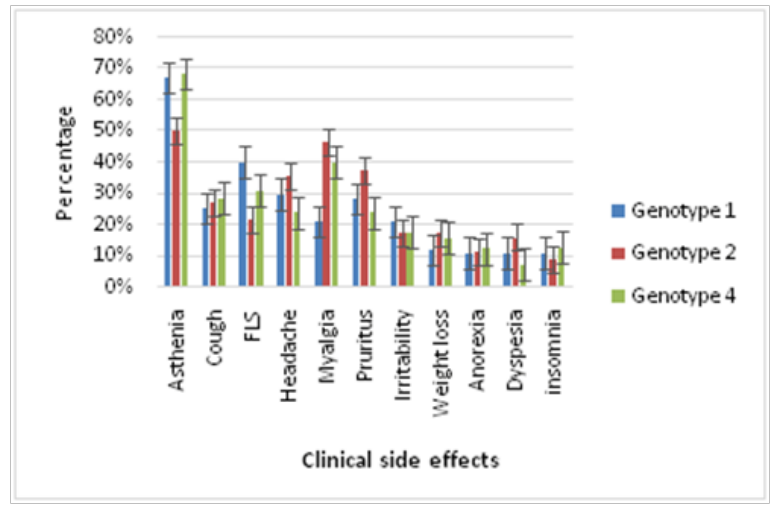

Figure 2 Distribution of major clinical side effects among the genotypes (FLS: Flu-Like Syndrome).

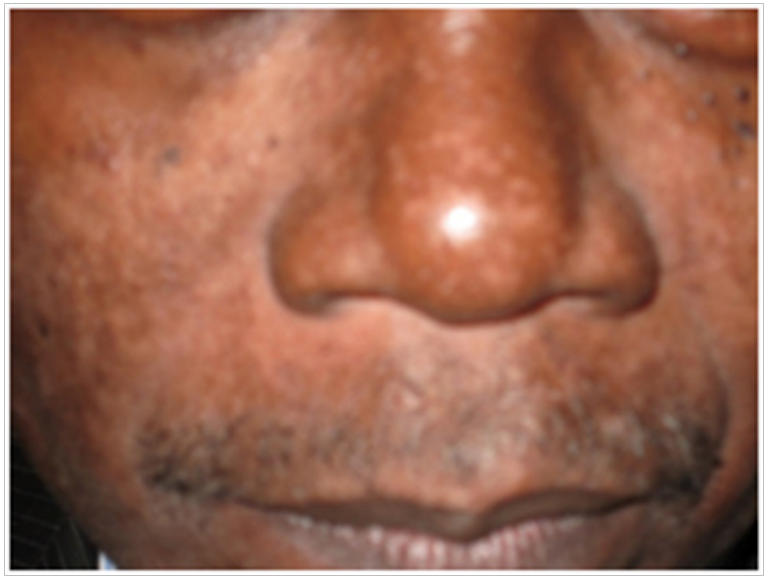

Figure 3 Acromia in a genotype 2 patient.

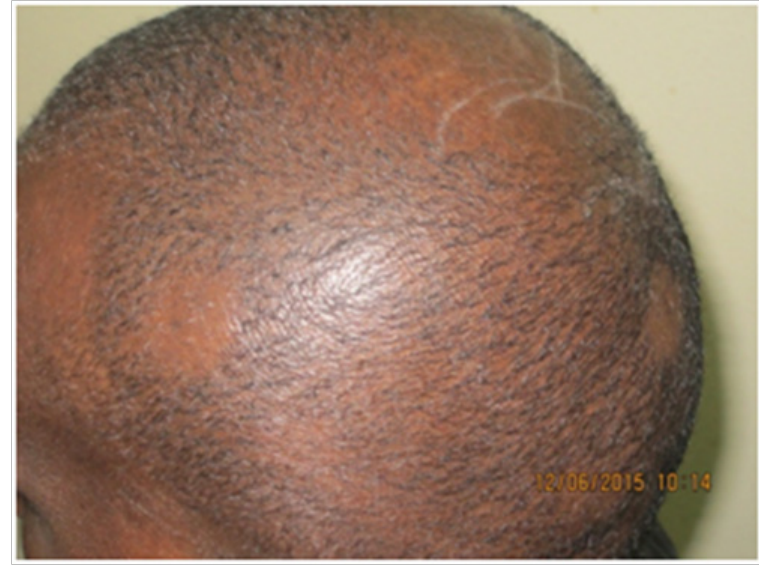

Figure 4 Irregular alopecia in a genotype I patient.

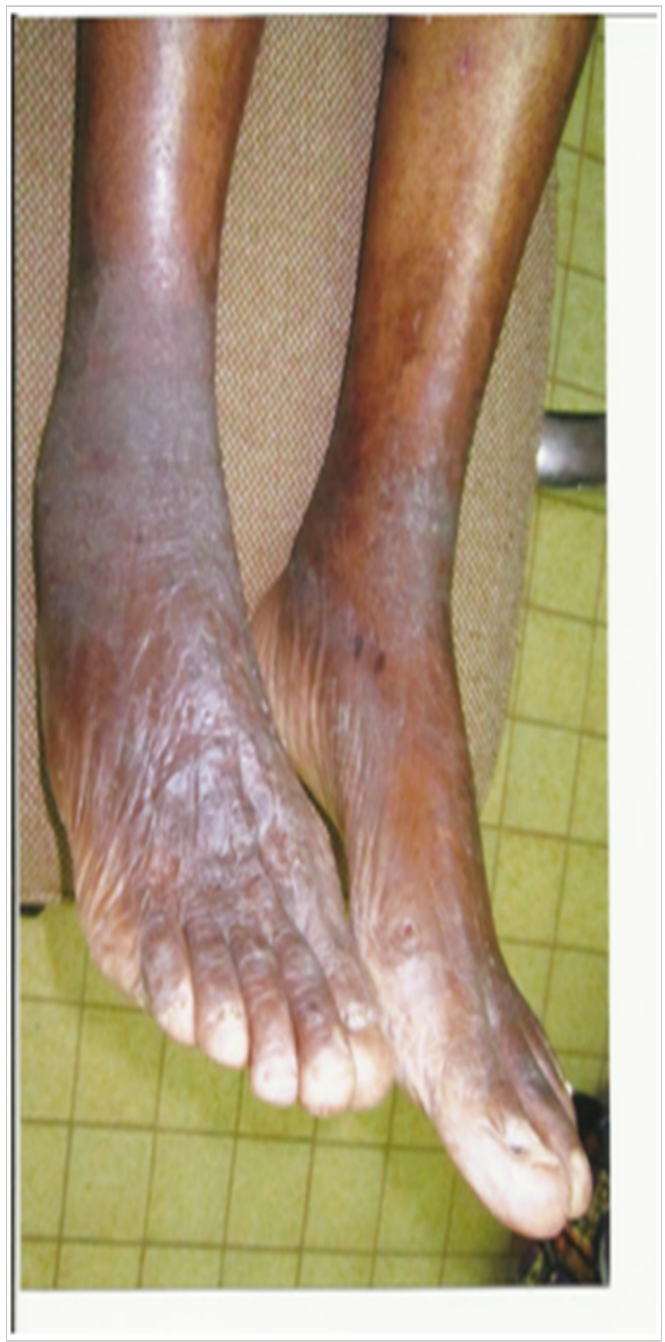

Figure 5 Eczema on the legs of a genotype 4 patients.

Biological adverse events: The most biological adverse events were of hematologic origin. It happened very rapidly, before the 5 th week. All patients presented at least a grade1 anemia $(9.5-10.9 \mathrm{~g} /$ $\mathrm{dLHb}$ ). Out of the 391 patients, $61.1 \%$ presented with neutropenia whereas thrombocytopenia was found in $30.9 \%$ of the patients. All these hematologic side effects had the tendency to stabilize after the 12th week (Figure 6 - Figure 8). Similarly to clinical aspects, the hematologic side effects did not differ according to genotype; they had meanwhile, a tendency to appear with time.

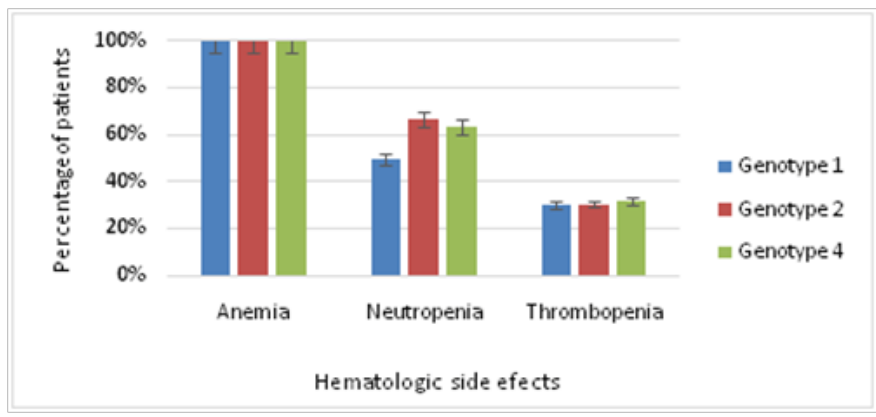

Figure 6 Distribution of hematologic side effects among the genotypes. 


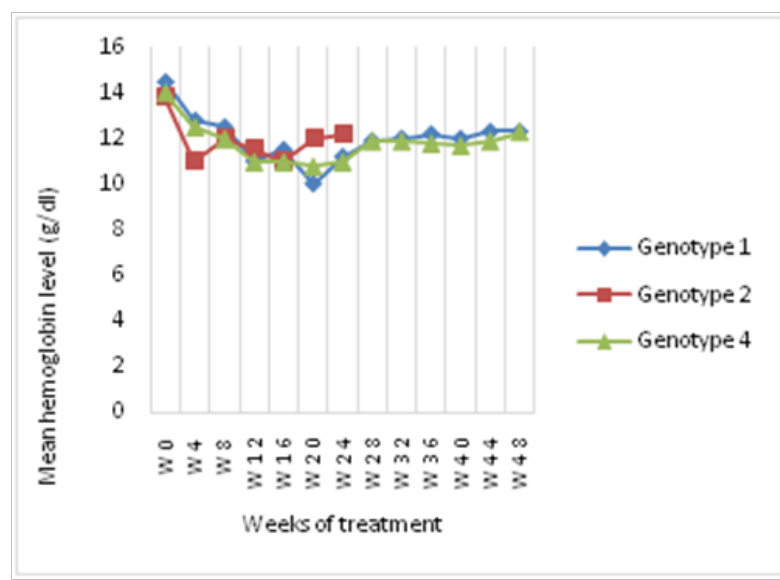

Figure 7 Evolution of mean hemoglobin level during treatment.

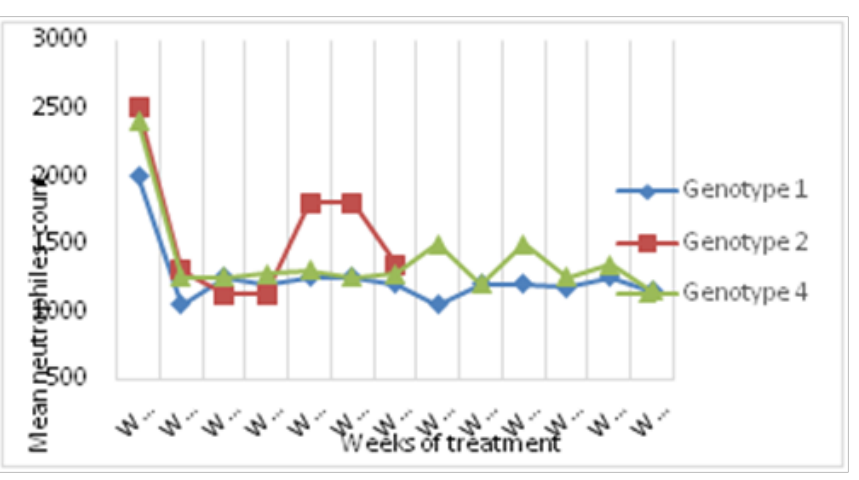

Figure 8 Evolution of neutrophiles count during treatment.

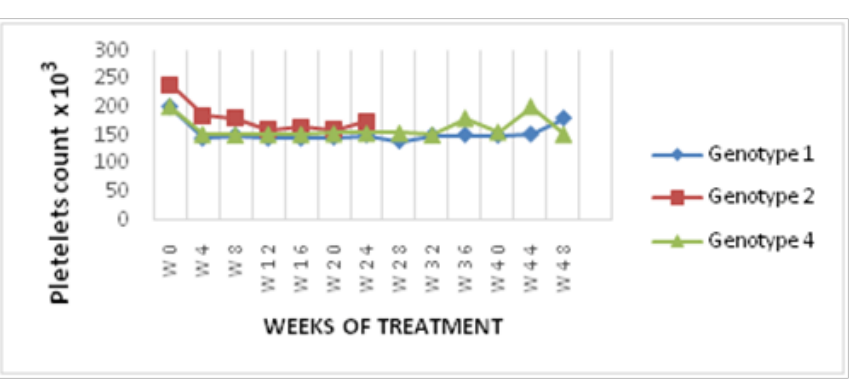

Figure 9 Evolution of mean platelets count during treatment.

\section{Discussion}

This study was aimed to describe the side effects of the combination of the Peg-Inf/RBV regimen in the treatment of chronic viral hepatitis $\mathrm{C}$ in black Africans. It was a multi centric study which included patients followed in the different centers of viral hepatitis treatment. The Peg-inf/RBV regimen is still in use in all the countries in the sub-Sahara region, pending the availability of direct acting antivirals (DAAs). Thus, the results of our study should be useful in management black Africans with chronic hepatitis C. Not so many studies were done on the side effects of the combination of Peg-inf RBV after those published in the mid-nineties and towards its end. The studies published by that period were mainly Caucasians-based experience. In the present study, we found a variety of clinical side effects, occurring generally by the 12th week of the treatment. Most of the clinical side effects are similar to those described by the manufacturer. Meanwhile, the incidence and the severity seemed to be peculiar in the blacks.

Asthenia and fatigue, besides that seen with the flu-like syndrome, was very frequent. This high rate (more than 60\%) has been reported by several authors. ${ }^{5-7}$ Though it could be mistaken with the manifestations of anemia, it rarely goes beyond grade 2 . They usually increase slowly in intensity over the first eight weeks of therapy. We did not observe variations in asthenia with drug doses as specified by the manufacturers, ${ }^{8}$ or as reported by other authors. ${ }^{9}$ This is because patients in our study had no variations in their drug dosage, and also, therapeutic observations stopped at forty-eight weeks. Asthenia has also been reported by patient whose blood count did not show marked anemia. Other reason explanation might be thyroid hormone related. ${ }^{10}$ The flu-like syndrome was found in more than $30 \%$ of patients, the peculiarity being that it was not constant in the same patient. This is why paracetamol was not systematically prescribed before injecting Peg-Inf. However, it has been shown to be efficient in times of need. Cough, seen in $30 \%$ of patients was often fitful, non productive, and difficult to treat with classical cough suppressants. Neuropsychiatric side effects in our patients were less frequent and less severe, compared to that reported in Caucasians. ${ }^{6}$ Depression was probably under reported as diagnostic tools often used was not validated for the African context. As a matter of facts, the diagnosis was limited to the behavioral component, without integration of the cognitive and somatic components mainly. ${ }^{11,12}$

Skin manifestations were frequently reported in the . We found skin modifications such as hyper pigmentation or acromia. The acromia was a non-homogenous reduction in skin pigmentation giving a clear aspect, slightly different from the reported vitiligo. ${ }^{14}$ This has not found in the literature, probably because it is difficult to diagnose in whites and patients with clear skin color. Despite a certain degree of esthetic problems, it was reversible at the end of treatment. Hematological manifestations were more frequent and preoccupying. Despite the generally moderate grade, hemolytic anemia due to ribavirin was found in all of our patients, and occurred as early as the fourth week of treatment. This was also reported in earlier studies in ,${ }^{, 16}$ and there was no difference between the genotypes. Neutropenia induced by Peg-inf occurred suddenly, and persisted for long. There was less variations later on, irrespective of the genotype. Neutropenia was more frequent in our patients compared to that reported by other authors, who reported rates between $9 \%$ and $25 \% .{ }^{17}$ It should however be noted that, normal values of the blood count differ between Blacks and Caucasians. ${ }^{18,19}$ It has been stated that Afro Americans have a significantly lower mean concentration of leukocytes and Neutrophils than the Caucasians ${ }^{20}$ If these peculiarities in some setting has led to lowering the threshold for dose modification, ${ }^{21}$ in our observations, we considered tolerability to evaluate the need to require pharmacological correction with Stimulating Factors. The prescription of stimulating factors increased the cost of treatment by about $10 \%$.

\section{Conclusion}

The characteristic features of adverse effects related to combination therapy using Pegylated interferon alfa-2a and ribavirin in the treatment of chronic HCV in the blacks, are similar to those indicated by the manufacturer. These adverse effects do not differ according to genotype, but tend to be in relation the duration of treatment. Some of them can become intractable, alternative treatment or psychological support from patients association can be therefore helpful. The selection of patients for treatment and the management of hematological side effects in the blacks should take into account, 
their natural peculiarities concerning the blood count in general The severity of the adverse effects or their combination can alter the quality of life and the adherence to treatment. There is a need for a multi-disciplinary approach to adapteach individual care.

\section{Acknowledgements}

None.

\section{Conflicts of interest}

The authors declare that there is no conflict of interest.

\section{References}

1. Gaglio PJ, Rodriguez-Torres M, Herring R, et al. Racial differences in response rates to consensus interferon in $\mathrm{HCV}$ infected patients naïve to previous therapy. J Clin Gastroenterol. 2004;38(7):599-604.

2. Njoya O, Essomba N, Essi MJ, et al. Therapeutic Response to Pegylated Interferon $\alpha-2 \mathrm{a}$ and Ribavirin in Genotype 4 Chronic Hepatitis $\mathrm{C}$ in Sub Saharan Africans. JSM Gastroenterol Hepatol. 2015;3(2):1041.

3. Njoya O, Ntsama L, Essi MJ, et al. Therapeutic Response of Black Africans in the Treatment of Genotype 2 Chronic Viral Hepatitis c by Pegylated Interferon-ribavirin. Austin J Gastroenterol. 2014;1(2):1009.

4. Nkuize Nkuize M, Mulkay JP, Adler M, et al. Response of Black African patients with chronic hepatitis $\mathrm{C}$ virus genoytype 4 to treatment with peg-interferon an ribavirin. Acta Gastroenterol Belg. 2013;76(3):291299.

5. Fontanges $\mathrm{T}$ Beorchia S, Douvin C, Delassalle P, et al. Safety and efficacy of combination therapy with peginterferon alfa-2a (40-kd) and ribavirin in the outpatient setting: Prospective analysis of 197 patients with chronic hepatitis c viral infection. Gastroenterol Clin Biol. 2007;31(6-7):566-572.

6. Reddy KR, Wright TL, Pockros PJ, et al. Efficacy and safety of pegylated (40-kd) interferon alpha-2a compared with interferon alpha-2a in noncirrhotic patients with chronic hepatitis C. Hepatology. 2001;33(2):433438.

7. McHutchison JG, Manns M, Patel K, et al. Adherence to combination therapy enhances sustained response in genotype-1-infected patients with chronic hepatitis C. Gastroenterology. 2002;123(4):1061-1069.

8. Jonasch E, Haluska FG. Interferon in oncological practice: review of interferon biology, clinical applications, and toxicities. Oncologist. 2001;6(1):34-55.
9. Arnaud P. Les différents interférons pharmacologie, mécanismes d'action, tolérance et effets secondaires. Rev Med Interne. 2002;23(Suppl. 4): $449 \mathrm{~s}-458 \mathrm{~s}$

10. Shaefer M, Mauss S. Management of adverse drug reactions. In: Mauss S, et al. (Eds.), Hepatology a clinical text book. Duesseldorf, Germany. Flying Publisher; 2015. p. 306-320.

11. Malaguarna M, Malaguarnera M, Di Fazio I, et al. Interferon alphainduced depression in chronic hepatitis $\mathrm{C}$ patients: Comparison between different types of interferon alpha. Neuropsychobiology. 1988;37(2):9397.

12. Renault PF, Hoofnagle JH, Park Y, et al. Psychiatric complication of long-term interferon alpha therapy. Arch Intern Med. 1987;147(9):15771580 .

13. Gournay J, Richou C. traitement de l'hépatite chronique C: effet secondaires, tolérance et qualité de vie. Gastroenerol clin Biol. 2002;26:B60-B75.

14. Dalekos GN, Christodoulou D, Kistis KG, et al. A prospective evaluation of dermatological side effects during Alpha-interferon therapy for chronic hepatitis C. Eur J Gastroenterol Hepatol. 1998;10(11):933-939.

15. Poinard P, Leroy V, Cohard M, et al. Meta-analysis of interferon randomized trials in the treatment of viral hepatitis C: Effects of dose and duration. Hepatology. 1996;24(4):778-789.

16. Tong MJ, Reddy KR, Lee WM, et al. treatment of chronic hepatitis C with consensus interferon: a multicenter randomized contolled trial. Hepatology. 1997;26(3):747-754.

17. Soza A, Everhart JE, Ghany MG, Doo E, Heller T, et al. (2002) Neutropenia during combination therapy of interferon alfa and ribavirin for chronic hepatitis C. Hepatology. 36(5):1273-1279.

18. Mbanya D, Nouthe B, Tayou Tagny C, et al. Transfusion de concentrés de globules rouges à Yaoundé, Cameroun: quelle qualité? Transfusion Clinique et Biologique. 2007;14(5):453-456.

19. Coetzee MJ, Writes R, van Zyl M, et al. Evaluation of a world health organization color scale for detection of anaemia in haematology clinic. $S$ A fr Med J. 2000190(5):489.

20. Reed WW, Diehl LF. Leukopenia neutropenia and reduced hemoglobin levels in healthy American blacks. Arch Intern Med. 1991;151(3):501505 .

21. Howell CD, Jeffers LS, Hu S, et al. Safety and adherence to peginterferon alpha-2a plus ribavirin in black Americans with chronic hepatitis C genotype 1. Gastroenterology. 2004;126:Suppl 2. 